\title{
Proposal for the correct management of the Life Cycle Assessment results from integrated municipal solid waste treatment
}

\author{
M. Schiavon, M. Ragazzi, E. C. Rada \& G. Merler \\ Department of Civil, Environmental and Mechanical Engineering, \\ University of Trento, Italy
}

\begin{abstract}
This study focuses on the application of the environmental part of the Life Cycle Assessment (LCA) approach to identify the best alternative among four solutions representing different integrated management systems for the treatment of municipal solid waste (MSW) fluxes. The comparison between the results is made in terms of the human toxicity potentials, with respect to other treatments, including mechanical-biological treatments (MBTs). However, findings from previous studies highlighted the potential risk deriving from the applications of MBTs in their conventional configurations. It may be important to consider the need for adopting additional methods, such as emission, dispersion and exposure models. These tools can improve the understanding of the potential constraints derived from the choice of an integrated solution for waste management and provide useful insights for the choice of the location of a plant, in order to protect fields, pasture and dwellings from potential contamination of soil, the food chain and air.
\end{abstract}

Keywords: LCA, human toxicity potential, mechanical-biological treatments, incineration, MSW, air pollutants.

\section{Introduction}

The European Directives 1999/31/EC and 2008/98/EC established more and more stringent limits for the amount of waste sent to landfills and brought new challenges into the management of waste $[1,2]$. In this framework, selective collection (SC) and the optimization of waste fluxes are prerequisites for the 
reduction of the waste flows sent to landfill. Education is also demonstrated to be extremely important to increase the environmental awareness of the population and, thus, achieve good SC performances [3, 4]. The exchange of information between different cities and countries about the waste management systems adopted is also particularly useful to improve the respective waste management systems $[2,5,6]$. The choice of an efficient way to manage waste and, thus, the research for the best valorisation, treatment and possible disposal systems moves from a detailed knowledge of the waste itself and from the opportunities offered by the market regarding the feasible treatments. For decision-making processes, Life Cycle Assessment (LCA) is a powerful set of tools that was originally developed to evaluate environmental impacts of products and industrial processes, but that has also been applied to other sectors, such as the management of municipal solid waste (MSW) and its related treatment alternatives.

LCA has been widely applied to the waste sector with the purpose of finding the best strategy to optimize the waste management [7]. Recent studies focused on this aspect, adopting the LCA tool to identify benefits and constraints deriving from the adoption of different options for the management of waste fluxes, for their treatment and the energy recovery [8-12].

The LCA applied to the waste management is a powerful decisional tool that gives indications for the writing and updating of waste management plans and for the assessment and reduction of the related environmental impacts. In fact, among several other applications, the LCA allows evaluating the energy and environmental efficiencies of a waste treatment system, the management of the recycling activities and the impact of the management of the waste depending on its composition.

Although the LCA allows the scale-up of constrains and emissions to the place where the plant under investigation is located, this approach is not suitable for defining local impacts, since its aims do not include the assessment of the risk deriving from the specific impacts an activity can entail on its surroundings. In this paper, special emphasis is given to the environmental component of the LCA applied to four scenarios developed to simulate four different strategies for the treatment of Residual Municipal Solid Waste (RMSW).

The final aim of this study is to highlight the need for integrating always the valuable results coming from an LCA analysis with an understanding of the mechanisms that lead to the final direct implications on human health. In particular, this paper focuses on the environmental part of the LCA, with special attention to one category of environmental indicators: the human toxicity potentials (HTPs). The need for additional tools, when undertaking LCAs of waste management systems, was already taken in consideration in the past years [13]. By the discussion on the results of the LCA here applied, a proposal for additional investigations will be suggested for a more detailed analysis of the impacts, with particular regards to the potential cancer risk, which the population settled in the vicinity of waste treatment facilities may be exposed to. 


\section{Materials and methods}

In order to evaluate benefits and constrains deriving from the application of the LCA approach to identify the preferable solution for an integrated waste management system, four hypothetical but realistic configurations of waste treatments were chosen. SC is at the basis of the waste fluxes for the four scenarios considered in this paper. In fact, the concepts of prevention, re-use, recycling, energy recovery and, only as a final step, disposal to landfill were taken into account for the definition of the four scenarios, responding to the indications of the Sixth Environment Action Programme of the European Community [14]. In particular, the here adopted SC model mirrors the system in use in a town of the North of Italy, where paper and cardboard, glass, metals, plastics, light packaging and the residual municipal solid waste (RMSW) are collected separately by a kerbside collection system.

In the first scenario (scenario 1), the wet fraction of the RMSW undergoes a bio-drying process, followed by gasification, with the addition of the lightest dry fraction and the impurities from SC, and energy production by combustion of the syngas, whilst the heaviest fraction is sent to landfill (Figure 1). The organic waste from SC undergoes anaerobic digestion (AD) with energy production and the digestate is mixed with green waste from SC and sent to post-composting.

In the second scenario (scenario 2), the following main fluxes can be identified: the wet fraction of the RMSW is sent to anaerobic digestion with energy production and post-composting; the organic waste from SC, in analogy with the previous scenario, undergoes $\mathrm{AD}$ with energy production and the digestate is mixed with green waste and with the digestate coming from AD of the wet fraction of the RMSW; the lightest dry fraction of RMSW is mixed with the impurities from SC, from the pre-treating of the organic waste and from the post-refining of the composting process; this mixed waste undergoes gasification and energy recovery, whilst the heaviest dry fraction of the RMSW is sent to landfill waste

The third scenario (scenario 3) is similar to the first one, with the only difference that the wet fraction of the RMSW is sent to thermal drying instead of bio-drying. The energy for the thermal drying process is provided by the AD of the organic waste from SC.

The last scenario (scenario 4) considers the same treatments of the previous ones for the organic and green waste from the SC (AD with energy production and post-composting), whilst the RMSW, the impurities from the refining of the post-composting process and paper, cardboard, plastics and light packaging residues from SC undergoes incineration with energy recovery. In this scenario, glass and metals residues are assumed to be disposed in a landfill (Figure 2).

For the LCA, typical data on the efficiencies of devices, of processes and recycling, energy consumption of each equipment, interception rates of materials from pre-treatments and refining, yields of the post-composting and bio-drying, reagent consumption and production of bottom ashes and flying ashes from incineration and gasification were retrieved from the scientific literature [15-20], from the legislation [21] and from waste management and waste treatment 
companies $[22,23]$. For the overall environmental part of the LCA, the following categories of impact were considered, all related to emissions into the atmosphere: global warming potential, human toxicity potential (HTP), photochemical ozone creation potential and acidification potential. In this paper, special attention is given to the human toxicity potential deriving from the four scenarios presented.

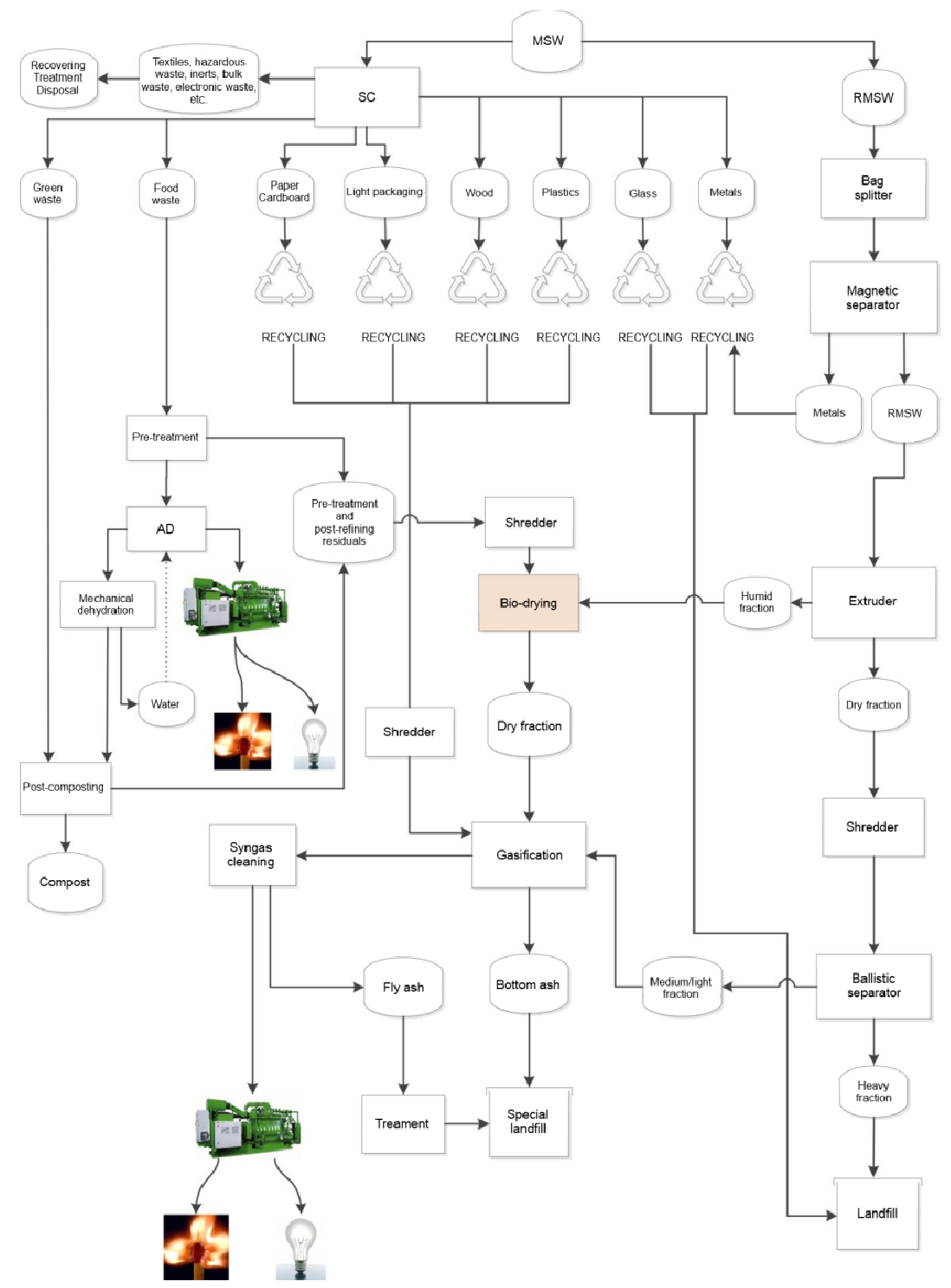

Figure 1: $\quad$ Scheme of the integrated waste management system considered in scenario 1 . 


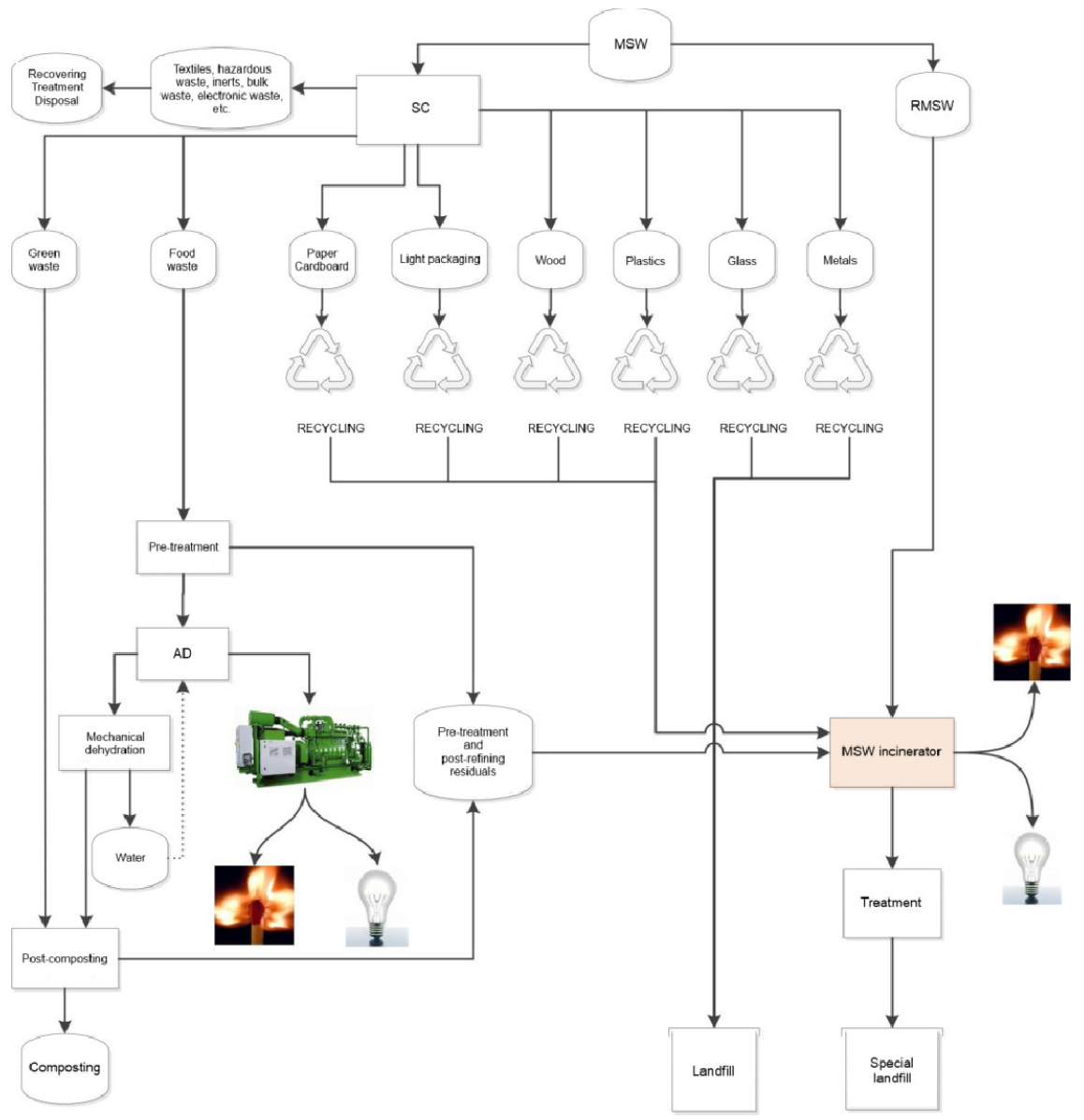

Figure 2: $\quad$ Scheme of the integrated waste management system considered in scenario 4.

From the environmental point of view, HTP is one of the most important categories of indicators for the assessment of energy recovery strategies from waste treatments. HTP is related to the effects of toxic compounds, released into the environment, on human health. Typical emission factors for all the processes involved in the four scenarios (AD and co-generation of electricity and heat, composting, disposal to landfill, bio-drying, thermal drying, incineration, gasification and syngas combustion) were obtained by previous studies and technical reports on Italian waste treatment facilities [24-28].

HTPs were calculated with the model USES-LCA, which describes the effects due to the release of 181 toxic compounds into different environmental matrixes using 20, 100 and 500 year time horizons [29]. In this specific case, the time horizon was set to 500 years. Emissions of interests for global warming potential were expressed in terms of emissions of carbon dioxide, ethylene and 
sulphur dioxide equivalents, respectively, whilst emission potentials of interest for HTP are expressed in terms of 1,4-dichlorobenzene equivalents. The avoided emissions due to recycling and energy production were obtained by a previous study in the literature [30].

All the calculations were carried out considering that the total amount of waste entering the four systems is $297,200 \mathrm{t} \mathrm{y}^{-1}$, which is the total amount generated in 2010 by the Italian province chosen as the reference for this study [2]. Waste compositions and SC rate were also taken from the 2010 statistics of the local authority [31]. The pollutants considered in this paper and their related impacts are presented in Table 1 . Since this study aims at providing a critical analysis of the results concerning the HTP of the LCA applied to integrated waste management systems, the discussion of the results will focus on the toxic emissions produced.

Some important simplifications were introduced to overcome the difficulties in retrieving detailed information on different aspects: due to the presence of similarities between the four scenarios concerning the logistics, the emissions related to the collection and transport of waste were not considered; the material for the construction of the waste treatment facilities was not taken into account; slag and ashes sent to landfill were assumed not to be able to generate significant emissions.

Table 1: Pollutants and related potentials considered in the estimation of the impacts of emissions in terms of toxicity for humans [29].

\begin{tabular}{cccc}
\hline Compound & $\begin{array}{c}\text { HTP } \\
{[\mathrm{kg} \mathrm{1,4-dichlorobenzene}} \\
\left.\mathrm{kg}^{-1} \text { emission }\right]\end{array}$ & Compound & $\begin{array}{c}\text { HTP } \\
{[\mathrm{kg} \mathrm{1,4-dichlorobenzene}} \\
\left.\mathrm{kg}^{-1} \text { emission }\right]\end{array}$ \\
\hline PCDD/Fs (I-TEQ) & $1.90 \mathrm{E}+09$ & $\mathrm{C}_{6} \mathrm{H}_{6}$ & $1.90 \mathrm{E}+03$ \\
Cr VI & $3.40 \mathrm{E}+06$ & $\mathrm{HF}$ & $2.90 \mathrm{E}+03$ \\
PAHs & $5.70 \mathrm{E}+05$ & $\mathrm{C}_{6} \mathrm{H}_{6}$ & $1.90 \mathrm{E}+03$ \\
$\mathrm{As}$ & $3.50 \mathrm{E}+05$ & $\mathrm{Cr} \mathrm{III}$ & $4.70 \mathrm{E}+02$ \\
$\mathrm{Cd}$ & $1.50 \mathrm{E}+05$ & $\mathrm{~Pb}$ & $1.00 \mathrm{E}+02$ \\
$\mathrm{Se}$ & $4.80 \mathrm{E}+04$ & $\mathrm{Zn}$ & $1.20 \mathrm{E}+00$ \\
$\mathrm{Ni}$ & $3.50 \mathrm{E}+04$ & $\left.\mathrm{NO}_{\mathrm{x}}(\mathrm{as} \mathrm{NO})_{2}\right)$ & $1.20 \mathrm{E}+00$ \\
$\mathrm{Co}$ & $1.70 \mathrm{E}+04$ & $\mathrm{PM}_{10}$ & $8.20 \mathrm{E}-01$ \\
$\mathrm{~V}$ & $6.20 \mathrm{E}+03$ & $\mathrm{HCl}$ & $5.00 \mathrm{E}-01$ \\
$\mathrm{Hg}$ & $6.00 \mathrm{E}+03$ & $\mathrm{H}_{2} \mathrm{~S}$ & $2.20 \mathrm{E}-01$ \\
\hline
\end{tabular}

\section{Results and discussion}

The resulting HTP contributions of the four scenarios here considered, in terms of produced emissions, are presented in Figure 3. All the emissions are expressed in tons of 1,4-dichlorobenzene equivalents. Considering the aims of the LCA, more exhaustive information is provided by the balance between the amounts emitted by the waste treatments and the emissions avoided thanks to the 
recycling and the lacking use of conventional sources for the production of heat and electricity. By an analysis on the net contributions, the results of the LCA pointed out the higher impacts of the waste incineration in terms of HTP. On the other hand, AD coupled with post-composting and gasification preceded by biodrying or thermal drying would contribute to net emissions corresponding to $6 \%$ of the amounts emitted by incineration (Figure 4).

\section{Human Toxicity Potential}

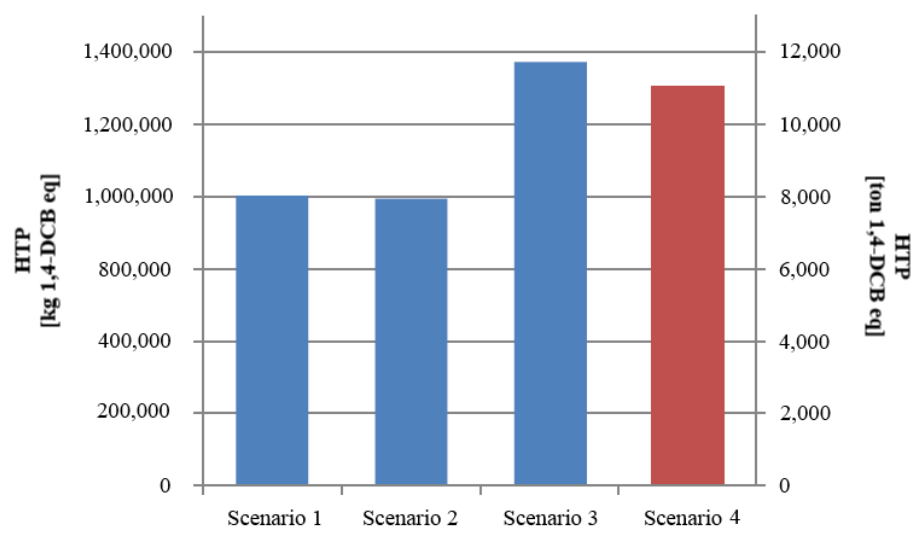

Figure 3: Emissions of interest for human toxicity, produced by each scenario in terms of 1,4-dichlorobenzene equivalents; due to the different order of magnitude, HTPs of scenarios 4 are expressed in tons of 1,4-dichlorobenzene equivalents (right scale).

\section{Human Toxicity Potential}

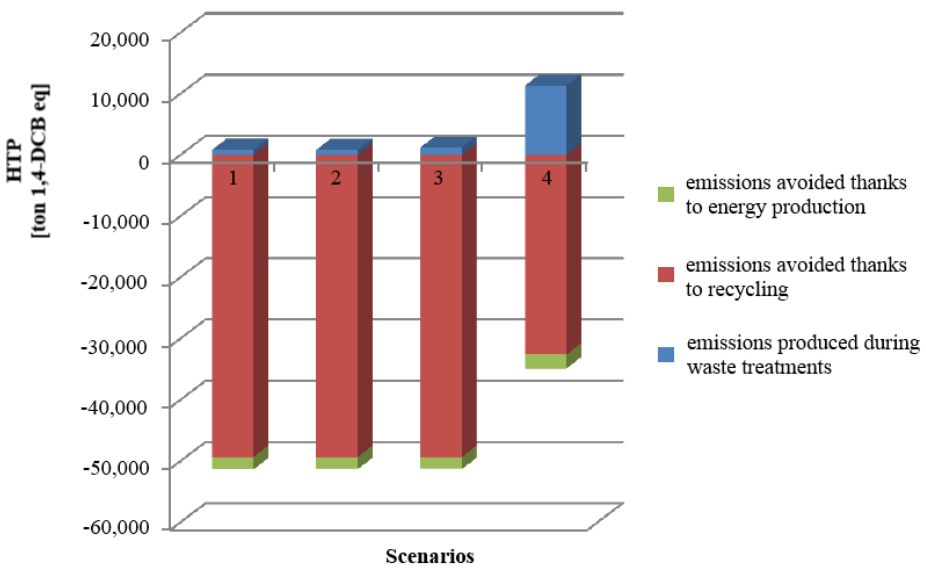

Figure 4: Emissions of interest for human toxicity produced by each scenario and detail of the emissions avoided. 
However, with respect to the impacts on human health, the choice of the best treatment from the environmental point of view should not be limited by the results of an LCA. Evidences coming from dispersion simulations based on the typical emission factors for the air treatment systems usually adopted by mechanical-biological treatment (MBT) plants show potentially high impacts on the surrounding areas [32-34]. The removal efficiencies of biofilters, for instance, coupled with the low velocity of the outgoing air, do not offer an appropriate dilution of the pollutants emitted into the atmosphere; in addition, biofilters are usually located at ground level. As a consequence, due to the absence of chimneys to increase the release height, the impacts of MBTs like bio-drying and biostabilization on ambient air concentration and atmospheric deposition to soil may be comparable with the impacts generated by the newest municipal waste incinerators $[33,35]$. In fact, even though the emissions from MBTs are lower, their impact on the population may be even higher both for the configurations of the usual removal technologies and due to the possible presence of fields, pastures and dwellings in the surroundings. Thus, from the point of view of the human toxicity, stopping the environmental assessment of an integrated MSW management system at the results of the LCA may take to misleading decisions and to underestimate the real local impacts of a plant on human health.

\section{Conclusions}

The results of an LCA applied to the choice of the most appropriate configuration of an integrated MSW management system were discussed with respect to the most important indicator in terms of risk for human health, the HTP. The comparison between the results, which pointed out the important role of MSW incinerators, and the findings of previous studies highlighted the need for additional assessment tools, since the sole LCA may not be enough for a correct interpretation of the results. Thus, in view of an as more complete as possible environmental assessment, it may be important to consider the need of adopting always additional methods that can improve the understanding of the potential constraints deriving from the choice of a specific integrated solution for waste management. Emission, dispersion and exposure models, for instance, are consolidated tools that give important indications on the impacts that can be expected by emission sources. Their integration into Geographical Information System platforms allows decision makers to spatially visualize the influence of a plant in terms of air quality. In addition, such tools provide useful insights for the choice of the location of a plant: this way, situations like the proximity to fields, pasture and dwellings can be avoided.

\section{Acknowledgements}

The Authors wish to thank the Fondazione Trentina per la Ricerca sui Tumori and, especially, the De Luca family for the financial support to this research activity. 


\section{References}

[1] Ionescu, G., Rada, E.C., Ragazzi, M., Mărculescu, C., Badea, A. \& Apostol, T., Integrated municipal solid waste scenario model using advanced pretreatment and waste to energy processes. Energy Conversion and Management, 76, pp. 1083-1092, 2013.

[2] Rada, E.C., Effects of MSW selective collection on waste-to-energy strategies. WIT Transactions on Ecology and the Environment, 176, pp. 215-223, 2013.

[3] Vaccari, M., Torretta, V. \& Collivignarelli, C., Effect of improving environmental sustainability in developing countries by upgrading solid waste management techniques: A case study. Sustainability, 4(11), pp. 2852-2861, 2012.

[4] Castagna, A., Casagranda, M., Zeni, A.,Girelli, E., Rada, E.C., Ragazzi, M. \& Apostol, T. 3R'S from citizens' point of view and their proposal from a case-study. UPB Scientific Bulletin, Series D, 75(4), pp. 253-264, 2013.

[5] Wilson, D.C., Rodic, L., Scheinberg, A., Velis, C.A. \& Alabaster, G., Comparative analysis of solid waste management in 20 cities. Waste Management \& Research, 30(3), pp. 237-254, 2012.

[6] Torretta, V., Ragazzi, M., Istrate, I.A. \& Rada, E.C., Management of waste electrical and electronic equipment in two EU countries: A comparison. Waste Management, 33(1), pp. 177-122, 2013.

[7] Cleary, J., Life cycle assessments of municipal solid waste management systems: A comparative analysis of selected peer-reviewed literature. Environment International, 35, pp. 1256-1266, 2009.

[8] Song, Q., Wang, Z. \& Li, J., Environmental performance of municipal solid waste strategies based on LCA method: a case study of Macau. Journal of Cleaner Production, 57, pp. 92-100, 2013.

[9] De Feo, G. \& Malvano, C., The use of LCA in selecting the best MSW management system. Waste Management, 29(6), pp. 1901-1915, 2009.

[10] Koroneos, C.J. \& Nanaki, E.A., Integrated solid waste management and energy production - a life cycle assessment approach: the case study of the city of Thessaloniki. Journal of Cleaner Production, 27, pp. 141-150, 2012.

[11] Tunesi, S., LCA of local strategies for energy recovery from waste in England, applied to a large municipal flow. Waste Management, 31(3), pp. 561-571, 2011.

[12] Ionescu, G. \& Rada, E.C., Material and energy recovery in a municipal solid waste system: Practical applicability. International Journal of Environment and Resource, 1(1), pp. 26-30, 2012.

[13] Evkall, T., Assefa, G., Björklund, A., Eriksson, O. \& Finnveden, G., What life-cycle assessment does and does not do in assessments of waste management. Waste Management, 27(8), pp. 989-996, 2007.

[14] European Commission, Sixth Environment Action Programme. European Commission - Environment, Brussels, Belgium, 2002. 
[15] Rada, E.C., Ragazzi, M. \& Badea, A., MSW Bio-drying : Design criteria from A 10 years research. UPB Scientific Bulletin, Series D, 74(3), pp. 209-216, 2012.

[16] Velis, C.A., Longhurst, P.J., Drew, G.H., Smith, R. \& Pollard, S.J.T., Biodrying for mechanical-biological treatment of wastes: A review of process science and engineering. Bioresource Technology, 100(11), pp. 2747-2761, 2009.

[17] Arena, U., Process and technological aspects of municipal solid waste gasification. A review. Waste Management, 32(4), pp. 625-639, 2012.

[18] Rigamonti, L., Grosso, M. \& Giugliano, M., Life cycle assessment of subunit composing a MSW management system. Journal of Cleaner Production, 18, pp. 1652-1662, 2010.

[19] Rada., E.C., Franzinelli, A., Taiss, M., Ragazzi, M., Panaitescu, V. \& Apostol, T., Lower heating value dynamics during municipal solid waste bio-drying. Environmental Technology, 28(4), pp. 463-470, 2007.

[20] Magagni, A., Linee guida del CITEC - Linee guida per la progettazione, realizzazione e gestione degli impianti a tecnologia complessa per lo smaltimento dei rifiuti urbani (Guidelines for the design, the construction and the management of complex treatment plants for urban waste). Hyper: Venice, Italy, 2007 (Italian).

[21] European Commission, Reference document on Best Available Techniques for the waste treatments industries. Joint Research Centre, Seville, Spain, 2006.

[22] Cogeneration, www.cogeneration.com.ua/img/zstored/J320V21_en.pdf

[23] HERA, www.gruppohera.it

[24] Consonni, S., Giugliano, M. \& Grosso, M., Alternative strategies for energy recovery from municipal solid waste Part B: Emission and cost estimates. Waste Management, 25(2), pp. 137-148, 2002.

[25] Giugliano, M., Definizione dei flussi di inquinanti atmosferici dell'attività di termovalorizzazione dei rifiuti e valutazione degli impatti con la tecnica del ciclo di vita (Definition of air pollutant flows from waste incineration and evaluation of the impact through Life Cycle Assessment techniques). Technical Report: Department of Environmental, Hydraulic, Infrastructures and Surveying Engineering, Politecnico di Milano, Italy, 2007 (Italian).

[26] Blengini, G.A. \& Fantoni, M., Life Cycle Assessment di scenari alternativi per il trattamento della FORSU (Life Cycle Assessment of alternative scenarios for the treatment of food waste). Proc. of Ecomondo 2009, Rimini, Italy, 28-31 October, 2009 (Italian).

[27] Bini, G., Magistro, S., Angelino, E., De Lauretis, R., Liburdi, R., Picini, P. \& Riva; G., Manuale dei fattori di emissione nazionali (Handbook of the national emission factors). Technical Report: Centro Tematico Nazionale Atmosfera Clima ed Emissioni in Aria (National Centre for Atmosphere, Climate and Emissions), Potenza, Italy, 2002 (Italian). 
[28] Rada, E.C., Istrate, I.A., Panaitescu, V., Ragazzi, M., Cirlioru, T.M. \& Apostol, T., A comparison between different scenarios of Romanian municipal solid waste treatment before landfilling. Environmental Engineering and Management Journal, 9(4), pp. 589-596, 2010.

[29] Huijbregts, M., Priority Assessment of Toxic Substances in the frame of LCA - Time horizon dependency in toxicity potentials calculated with the multi-media fate, exposure and effects model USES-LCA. Institute for Biodiversity and Ecosystem Dynamics, University of Amsterdam, Amsterdam, The Netherlands, 1999.

[30] Rigamonti, L., Grosso, M. \& Giugliano, M., Life cycle assessment for optimising the level of separated collection in integrated MSW management systems. Waste Management, 29(2), pp. 934-944, 2009.

[31] ADEP, www.adep.provincia.tn.it

[32] Schiavon, M., Ragazzi, M., Rada, E.C. \& Torretta, V., New design criteria for biostabilization plants based on an unconventional parameter. Proc. of $14^{\text {th }}$ International Waste Management and Landfill Symposium, Cagliari, Italy, 30 September - 4 October, 2013.

[33] Rada, E.C., Ragazzi, M., Zardi, D., Laiti, L. \& Ferrari, A., PCDD/F environmental impact from municipal solid waste bio-drying plant. Chemosphere, 84(3), pp. 289-295, 2011.

[34] Ragazzi, M., Rada, E.C. \& Antolini, D., Material and energy recovery in integrated waste management systems: An innovative approach for the characterization of the gaseous emissions from residual MSW bio-drying. Waste Management, 31(9-10), pp. 2085-2091, 2011.

[35] Rada, E.C., Ragazzi, M., Panaitescu, V., Apostol, T., Some research perspectives on emissions from bio-mechanical treatments of municipal solid waste in Europe. Environmental Technology, 26(11), pp. 1297-1302, 2005. 